\title{
Peer Review Processes and Desirable Attitudes for Peer Reviewers
}

\author{
Kyu Jin Chung
}

Deputy Editor, Archives of Plastic Surgery

Department of Plastic and Reconstructive Surgery, Yeungnam University Hospital, Daegu, Korea

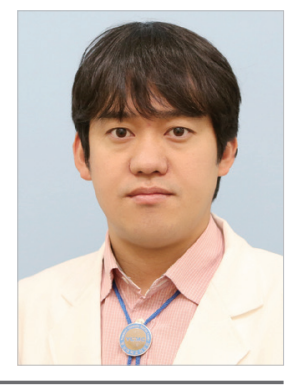

The peer review process refers to the meticulous inspection of a research paper by experts in the same field. This procedure is required to prevent the dissemination of uncertain research results and incorrect conclusions or interpretations. One of the purposes of the peer review process is to determine whether to accept or reject a publication, and another purpose is to strengthen the manuscript. If there are errors that can be corrected, publication after revision can be considered. However, if there are uncorrectable flaws, the manuscript should be rejected. The criteria for the review of a submission include its timeliness regarding the most recent advances in the field, comprehensibility, and the use of proper methodology [1].

Fairness of the entire review process is of utmost importance. Currently, single-blind review, double-blind review, and open peer review are used for peer review in scientific journals [2]. Single-blind review involves only an anonymous reviewer conducting the review. In single-blind reviews, the reviewers can freely express their opinions thanks to their anonymity. In a double-blind review process, the reviewer and the author remain anonymous. Such a peer review process allows the reviewer to evaluate the research paper purely based on its academic value, without being influenced by the author or the author's affiliation. However, problems with the current blind peer review process include delays, high cost, subjectivity, bias, non-educational aspects, and difficulties in identifying errors.

Author-guided open peer review is when the author directly chooses an expert to review his or her research paper. This process encourages collaboration between the author and the reviewer, allows for a dynamic evaluation, and reduces publication costs. In addition, this process allows a high-quality, helpful review to be provided.
The peer reviewer must be someone who has sufficient professional knowledge in the given field. The ideal professional reviewer is less than 40 years old, is affiliated with an excellent institution, and is well versed in subjects related to statistics and epidemiology [3]. The reviewer must accept the review request only if he or she has sufficient knowledge regarding the paper. If the reviewer has insufficient knowledge regarding the paper, has a conflict of interest, or is researching a similar subject, he or she must decline the review request. The reviewer must clearly inform the journal about the reviewer's professional subject area and reviewable subjects so that the journal can properly select reviewers.

Reviewer must complete a relevant and constructive review punctually. All conflicts of interest, including potential conflicts, must be fully revealed. The review must be honest and unbiased. If there is a limitation or a delay in the review process, the editor must be informed immediately. The content of the manuscript that is being reviewed must be kept confidential. In addition, the content of the review provided to the author and the content provided to the editor must be kept separate. The reviewer should consider the following guidelines: point out large matters first; point out each area of concern in a down-to-earth manner; sufficiently acknowledge the importance of the research in the introduction; make precise points; address potential weaknesses; mention omissions; and write in a manner that does not reveal the intentions or results of the review [4].

The review must not be affected by non-academic factors, such as the author's nationality, race, or gender. There must be no contact with anyone who is related to the manuscript, including the author, without informing the journal. The review must not request the author to cite a paper written by the re- 
viewer. The contents of the review must not contain personal disdain towards the author. The content of the reviewed paper must not be used for the reviewer's personal gain. Finally, the reviewer must not plagiarize the paper, even if it has not been published yet.

Archives of Plastic Surgery (Arch Plast Surg, APS) provides guidelines for reviewers, entitled 'How to Review a Manuscript Submitted to APS.' The components of each paper, such as the cover letter, abstract, introduction, methods, results, conclusions, acknowledgements, figures, graphs, tables, and references may be evaluated individually, in addition to an evaluation of the paper as a whole.

The abstract is the most important part of the manuscript. The reviewers should check whether the abstract adequately summarizes the contents of the manuscript. The reader should be able to understand the content of the paper through the abstract alone, without reading the rest of the paper. The purpose should be clearly stated in the introduction. The reviewer should check the reasonableness of the research and whether the research is thoroughly explained with reference to the existing literature. The methods should be described appropriately. The replicability of the described procedure and the applicability of the design should both be evaluated. If approval from the Institutional Review Board is required, the reviewer should also verify its presence and the suitability of the statistical procedures. The results should be clearly expressed. The reviewers should check whether all figures and tables are necessary. The reviewer should check for consistency in the main text, tables, and figures. The conclusions should follow from the results and/or the literature review. In addition, the papers that were used to support the author's points should be checked for their suitability. The reviewer should also check to see whether the conclusion is an appropriate answer to the question posed by the paper. When evaluating the paper as a whole, the reviewers should check whether the flow of arguments is logical.

APS invites international reviewers to take part in the review process and aims to further the education of reviewers by creat- ing review guidelines to strengthen the current peer review system. More efforts should be made for APS to become a more influential academic journal by keeping up to date with novel developments in the peer review process in the future.

\section{ORCID}

Kyu-Jin Chung http://orcid.org/0000-0001-6335-1818

\section{REFERENCES}

1. Kliewer MA, Freed KS, DeLong DM, et al. Reviewing the reviewers: comparison of review quality and reviewer characteristics at the American Journal of Roentgenology. AJR Am J Roentgenol 2005; 184:1731-5.

2. Provenzale JM, Stanley RJ. A systematic guide to reviewing a manuscript. AJR Am J Roentgenol 2005; 185:848-54.

3. Publishing Research Consortium. Peer review in scholarly journals: an international study into the perspective of the scholarly community [Internet]. Bristol, UK: Mark Ware Consulting Ltd; 2017 [cited 2017 Feb 25]. Available from: http://publishingresearchconsortium.com/index.php/112prc-projects/research-reports/peer-review-in-scholarly-journals-research-report/142-peer-review-in-scholarly-journalsperspective-of-the-scholarly-community-an-internationalstudy.

4. Lee SY. Tips on writing and reviewing articles as a non-english speaking medical doctor. Arch Plast Surg 2015;42:1-3.

Correspondence: Kyu Jin Chung

Department of Plastic and Reconstructive Surgery, Yeungnam University Hospital, 170 Hyeonchung-ro, Nam-gu, Daegu 42415, Korea

Tel: +82-53-620-3480, Fax: +82-53-626-0705, E-mail: guzy7@ hanmail.net

No potential conflict of interest relevant to this article was reported.

Received: 25 Feb 2017 • Revised: 27 Feb 2017 • Accepted: 28 Feb 2017

pISSN: 2234-6163 • elSSN: 2234-6171

http://dx.doi.org/10.5999/aps.2017.44.3.177 • Arch Plast Surg 2017;44:177-178 